\title{
Location, Location, Location: The Rural- Urban Divide in Intracerebral Hemorrhage Mortality
}

Roland Faigle ${ }^{*}$ (1)

C 2020 Springer Science+Business Media, LLC, part of Springer Nature and Neurocritical Care Society

Inequities in healthcare quality and outcomes are pervasive in the USA. Geographic location has been increasingly recognized as an important, and arguably modifiable, determinant of health. Approximately $15-20 \%$ of the US population live in rural areas. People living in rural communities generally have poorer health compared to urban dwellers, in part due to differences in access to high-quality care $[1,2]$.

In this issue of Neurocritical Care, Otite et al. [3] leverage administrative data from the 2004-2014 Nationwide Inpatient Sample (National Inpatient Sample) to examine rural-urban differences in in-hospital mortality after intracerebral hemorrhage (ICH). Among the 131,992 included ICH admissions, the authors found that ageand sex-adjusted in-hospital mortality was significantly higher among rural compared to urban dwellers across the entire study period $(32.2 \%$ vs. $26.5 \%$; $p<0.001)$; the mortality difference was even higher when only considering $2010-2014$ data $(32.0 \%$ vs. $24.6 \%, p<0.001)$. It is noteworthy that the true effect size of the mortality difference may be even higher considering that $\mathrm{ICH}$ patients in rural hospitals had lower case severity. In fully adjusted models, ICH patients receiving care in rural hospitals had over twofold higher odds of mortality compared to patients receiving care in urban hospitals (OR 2.07, 95\% CI 1.77-2.41). The direction and magnitude of the observed differences remained the same after excluding

\footnotetext{
*Correspondence: rfaigle1@jhmi.edu

Department of Neurology, Center for Health Equity, Johns Hopkins University School of Medicine, 600 N Wolfe Street, Phipps 484, Baltimore, MD 21287, USA

This comment refers to the article available at https://doi.org/10.1007/ s12028-020-00950-2.
}

patients receiving palliative care. Even more concerning is the observed divergent temporal trend. While there was an average annual percentage decrease in in-hospital ICH mortality of nearly $3 \%$ in urban hospitals, the mortality risk in rural hospitals did not change significantly over the study period, resulting in an increasing ruralurban mortality gap over time.

Otite et al.s data are disconcerting not only at face value, but even more so in the context of consistently decreasing overall in-hospital ICH mortality rates in the USA over recent years $[4,5]$. These data suggest that the nationwide decreasing $\mathrm{ICH}$ mortality rates are largely driven by urban hospitals, while patients receiving care in rural hospitals are left behind. As so often with studies suggesting inequities in outcomes, the critical question remains: What is the underlying cause of this disparity and how do we fix it? The use of administrative data has limitations, as discussed by the authors, and this study cannot explain the underlying mechanisms and causes that may have led to the observed rural-urban mortality differences. However, in-hospital mortality is a quality measure of hospital care commonly used by Centers for Medicare and Medicaid Services and hospital rankings, and differences in access to high-quality inpatient care are a likely cause of the observed rural-urban disparities in Otite et al's study.

Challenges in timely access to emergency care in rural communities are obvious: Larger hospital service areas and wider geographical area coverage by ambulances result in longer response and transport times by emergency medical services. Once in the hospital, rural $\mathrm{ICH}$ patients are less likely to receive timely access to neurocritical care units and providers with expertise in neurocritical care, vascular neurology, and neurosurgery $[6$,

\section{Springer}


7]. Structural challenges in rural hospitals commonly go beyond staffing. This includes resource limitations and a paucity of protocols streamlining the implementation of evidenced-based care, such as timely blood pressure control and access to pharmacological agents for coagulopathy reversal. For example, four-factor prothrombin complex concentrate (PCC) is frequently not stocked in pharmacies of smaller hospitals. Similarly, Idarucizumab, the reversal agent for Dabigatran-associated $\mathrm{ICH}$, is available in just over half of all US hospitals (as of May, 2018) [8], and even fewer hospitals have access to Andexanet Alfa. Taken together, lack of timely access to resources and specialist care may result in delay in blood pressure control, coagulopathy reversal, cerebral edema treatment, and surgical interventions, such as external ventricular drains for hydrocephalus, thus increasing the risk of hematoma expansion and clinical deterioration.

What are the potential solutions? There is not a single one-size-fits-all solution; however, inequities in stroke care due to care location require a concerted effort on an individual level as well as system level. Some rural institutions have started innovative initiatives to address a lack of resources. An example of such an initiative is air ambulance delivery of PCC from a tertiary center to resource-limited hospitals in rural Mississippi for expedited coagulopathy reversal [9]. While this is one example of an admirable single-institution effort to address a focused need on a relatively small scale, lasting and widespread efforts to increase access to high-quality care in rural communities require structural systems of care and policy changes.

Tele-neurocritical care may be a cost-effective and sustainable solution to the access and resource limitations that may be at the heart of Otite et al.s results. Since many rural hospitals already utilize tele-stroke services, the additional cost, technological burden, and administrative resources needed to implement tele-neurocritical care services are relatively low. An added advantage may be expedited triaging and identification of patients who benefit from transfer to a tertiary center, while preventing futile transfers. Despite having become an integral part of mainstream clinical practice, sustainable implementation of tele-neurocritical care still faces legal and regulatory barriers in some states, particularly surrounding licensing and credentialing, malpractice liability, and reimbursement [10].

Last but not least, the elephant in the room: The extinction of rural hospitals. Over the last decade, nearly 100 rural hospitals have closed doors, and a significant number of the remaining rural hospitals are at the brink of collapse [11]. The reasons for rural hospital closures are complex. Yes, it is (mostly) about money. Patients receiving care in rural hospitals tend to be older and have more chronic comorbidities. On the flipside, hospitals in rural communities provide care to a higher proportion of patients covered under Medicare and Medicaid with lower reimbursement rates. Similarly, rural hospitals care for a higher number of uninsured patients, particularly in states that have refused Medicaid expansion [12]. In short, patient needs are high, reimbursement is low. Hospital closures have resulted in healthcare deserts across rural America and can be linked directly to worse outcomes and increases in mortality in rural communities, including mortality related to stroke [13]. Policy-level solutions are desperately needed. A systemic overhaul of the healthcare system to provide high-quality affordable care to all patients, including underserved rural populations, is necessary. Health policy experts as well as elected officials have become increasingly sensitive to the urgency of healthcare reform, as indicated by a recent positioning paper by the American College of Physicians [14], and the emphasis on health care during contemporary political discourse. The time for action is now!

\section{Source of Support}

This study was funded by National Institute of Neurological Disorders and Stroke (Grant Number K23 NS101124).

\section{Publisher's Note}

Springer Nature remains neutral with regard to jurisdictional claims in published maps and institutional affiliations.

Published online: 30 March 2020

References

1. Martino SC EM, Dembosky JW, Hambarsoomian K, Burkhart Q, Klein DJ, Gildner J, Haviland AM. Rural-urban disparities in health care in medicine [online]. Available at: https://www.cms.gov/files/document/rural-urban -disparities-health-care-medicare-national-report. Accessed 22 Jan 2020.

2. Meit M KA, Gilbert T, Tzy-Chyi Yu A, Tanenbaum E, Ormson E, TenBroeck S, Bayne A, Popat S. The 2014 update of the rural-urban chartbook [online]. Available at: https://ruralhealth.und.edu/projects/health-reform-polic y-research-center/pdf/2014-rural-urban-chartbook-update.pdf. Accessed 22 Jan 2020.

3. Otite FO, Akano EO, Akintoye E, Khandelwal P, Malik AM, Chaturvedi S, Rosand J. Rural-urban disparities in intracerebral hemorrhage mortality in the United States. Neurocrit Care. 2020.

4. Otite FO, Khandelwal P, Malik AM, Chaturvedi S, Sacco RL, Romano JG. Ten-year temporal trends in medical complications after acute intracerebral hemorrhage in the united states. Stroke. 2017;48:596-603.

5. Ovbiagele B. Nationwide trends in in-hospital mortality among patients with stroke. Stroke. 2010;41:1748-54.

6. Diringer MN, Edwards DF. Admission to a neurologic/neurosurgical intensive care unit is associated with reduced mortality rate after intracerebral hemorrhage. Crit Care Med. 2001;29:635-40.

7. Ward MJ, Shutter LA, Branas CC, Adeoye O, Albright KC, Carr BG. Geographic access to US Neurocritical Care Units registered with the Neurocritical Care Society. Neurocrit Care. 2012;16:232-40.

8. Ingelheim B. Praxbind ${ }^{\circledR}$, Specific Reversal Agent for Pradax ${ }^{\circledR}$, now available in 3200 hospitals nationwide [online]. Available at: https:// www.prnewswire.com/news-releases/praxbind-specific-reversal-agent 
-for-pradaxa-now-available-in-3-200-hospitals-nationwide-300642550. html. Accessed 22 Jan 2020

9. Vines C, Tesseneer SJ, Cox RD, Darsey DA, Carbrey K, Puskarich MA. Air ambulance delivery and administration of four-factor prothrombin complex concentrate is feasible and decreases time to anticoagulation reversal. Acad Emerg Med. 2018;25:33-40.

10. Klein KE, Rasmussen PA, Winners SL, Frontera JA. Teleneurocritical care and telestroke. Crit Care Clin. 2015;31:197-224.

11. M O. Here's why rural hospitals are shutting down more quickly in these states [online]. Available at: https://www.huffpost.com/entry/rural-hospi tals-close-medicaid-aca_b_5c4734d8e4b09dd3f0cb1f08. Accessed 22 Jan 2020.
12. Office USGA. Rural hospital closures: number and characteristics of affected hospitals and contributing factors [online]. Available at: https:// www.gao.gov/assets/700/694125.pdf. Accessed 22 Jan 2020.

13. Gujral K BA. Impact of rural and urban hospital closures on inpatient mortality [online]. Available at: https://www.nber.org/papers/w26182.pdf. Accessed 22 Jan 2020.

14. Doherty R, Cooney TG, Mire RD, et al. Envisioning a better U.S. health care system for all: a call to action by the American College of Physicians. Ann Intern Med. 2020;172:S3-6. 